\title{
MODELOS DE TOMADA DE DECISÃO DO CONSUMIDOR, DESTACANDO OS ASPECTOS APLICÁVEIS AOS SERVIÇOS FINANCEIROS E OS QUE REQUEREM ADAPTAÇÃO.
}

\section{MODELS OF CONSUMER DECISION-MAKING, HIGHLIGHTING ASPECTS APPLICABLE TO FINANCIAL SERVICES AND THOSE REQUIRING ADAPTATION.}

\author{
Evandro Ferigato ${ }^{1}$
}

\author{
Submetido: 10/01/2021 \\ Aprovado: 19/01/2021
}

\begin{abstract}
RESUMO
Reconhece-se que as teorias existentes sobre Modelos de Tomada de Decisão do Consumidor (MTDC) não são adequadas para serviços financeiros e houve pedidos para o desenvolvimento de um novo modelo conceitual. Este artigo analisa modelos proeminentes de MTDC e identifica pontos fortes e limitações. Um novo modelo conceitual aplicável aos serviços financeiros é desenvolvido. Um elemento importante do modelo é o reconhecimento de que os componentes interagem em vez de um consumidor após uma progressão linear através de uma série de estágios. O novo modelo reflete melhor o processo iterativo de tomada de decisão relevante para os serviços financeiros e aprimora a compreensão do processo pelos profissionais de marketing e, portanto, sua capacidade de influenciá-lo para aumentar a probabilidade de resultados positivos para todos. O modelo possui três componentes principais: entradas, processos e resultados. As entradas incluem a situação da compra (variáveis contextuais e ambientais), características do consumidor (influências psicológicas e sociais) e fontes de informação (mix de marketing e interpessoal). Os processos incluem necessidade de excitação, utilidade da informação, desenvolvimento de critérios e avaliação de alternativas. Os resultados incluem a decisão (que pode ser, abortar a compra), a compra em si e a avaliação pós-decisão. Mais pesquisas são necessárias para testar os relacionamentos entre as variáveis em diferentes contextos e, assim, permitir o refinamento e/ou validação do modelo.
\end{abstract}

PALAVRAS-CHAVE: Serviços financeiros. Comportamento do comprador do modelo de tomada de decisão do consumidor. Estratégia de Marketing para Consumidores.

\begin{abstract}
It is recognized that the existing theories on Consumer Decision Making Models (CDMM) are not suitable for financial services and there have been calls for the development of a new conceptual model. This article looks at prominent CDMM models and identifies strengths and limitations. A new conceptual model applicable to financial services is developed. An important element of the model is the recognition that the components interact instead of a consumer after linear progression through a series of stages. The new model better reflects the iterative decision-making process relevant to financial services and improves marketers' understanding of the process and therefore their ability to influence it to increase the likelihood of positive results for everyone. The model has three main components: inputs, processes and results. Entries include the purchase status (contextual and environmental variables), consumer characteristics (psychological and social influences) and information sources (marketing and interpersonal mix). The processes include the need for excitement, usefulness of information, development of criteria and evaluation of alternatives. The results include the decision (which may be to abort the purchase), the purchase itself and the postdecision evaluation. More research is needed to test the relationships between variables in different contexts and, thus, allow the refinement and/or validation of the model.

\footnotetext{
1 Professor MBA Pós-Graduação e Graduação UNIFACCAMP e FFRAMO; Mestre Administração; PósGraduado Gestão de Pessoas; Pós-Graduado Logística; Graduado Logística; Graduado Publicidade e Propaganda; Administração de Micro e Pequenas Empresas; UNIFACCAMP - Centro Universitário Campo Limpo Paulista.
} 


\section{RECIMA21 - REVISTA CIENTÍFICA MULTIDISCIPLINAR}

MODELOS DE TOMADA DE DECISÃO DO CONSUMIDOR, DESTACANDO OS ASPECTOS APLICÁVEIS AOS SERVIÇOS FINANCEIROS E OS QUE REQUEREM ADAPTAÇÃO. Evandro Ferigato

KEYWORDS: Financial services. Buyer behavior of the consumer decision-making model. Marketing Strategy for Consumers.

\section{INTRODUÇÃO}

Os conceitos contidos nos Modelos de Tomadas de Decisão do Consumidor (MTDC) e os relacionamentos entre eles são complexos. Desde os primeiros modelos na década de 1960, as estruturas para os MTDC evoluíram de várias formas, mas os modelos mais comumente aceitos ainda não se relacionam bem a produtos como serviços financeiros.

Houve um pedido de um modelo de tomada de decisão do consumidor para serviços financeiros nos últimos anos. Por exemplo, em 1992, McKechnie sugeriu que "... há uma notável ausência de qualquer estrutura conceitual geral que descreva como os consumidores compram serviços em geral, muito menos serviços financeiros em particular" (1992, p. 11). Mais recentemente, Byrne (2005) observou que a tomada de decisão do consumidor por produtos financeiros recebeu pouca atenção, mas que é um tópico com clara importância prática. Harrison, Waite e White ecoam o sentimento, afirmando que "... houve pouca tentativa de desenvolver um modelo de comportamento do consumidor especificamente para explicar os processos de decisão do consumidor em relação a serviços financeiros complexos, como pensões" (2006, p. 7).

Esta pesquisa atende a uma necessidade crescente à medida que os serviços financeiros se tornam mais proeminentes na sociedade. Mudanças na demografia, gastos do governo e clima econômico estão exigindo que os indivíduos tomem decisões importantes em relação ao seu futuro financeiro (Hazel Bateman, Kingston e Piggott, 2001; Gough e Sozou, 2005). A riqueza gerada pelas nações desenvolvidas na história recente significa que há uma demanda por serviços financeiros sem precedentes. Além disso, o envelhecimento da população apresenta um problema para os governos ocidentais, pois eles terão dificuldade em fornecer níveis de serviço equivalentes às gerações anteriores em termos de pensão e assistência médica (Bryant, 2004; Disney, 1996). No passado, os impostos e outras receitas levantadas pelos governos eram suficientes para fornecer a proporção relativamente pequena da população que recebe pensões. No entanto, o Baby Boomers representa uma porcentagem tão grande da população, em alguns países até 30\%, que os impostos levantados do restante da população não serão suficientes para apoiar esse grupo (Bryant, 2004; R. Lee \& Skinner, 1999). Devido a esses desenvolvimentos, a responsabilidade de planejar a aposentadoria será transferida, movendo-se cada vez mais para o consumidor ou para a autogestão dos ativos de aposentadoria (Hazel Bateman \& Piggott, 2000; Hazel Bateman \& Piggott, 2003). Para apoiar indivíduos nesse contexto de mudança, existe uma necessidade de mais conhecimento na área de tomada de decisão em serviços financeiros. 


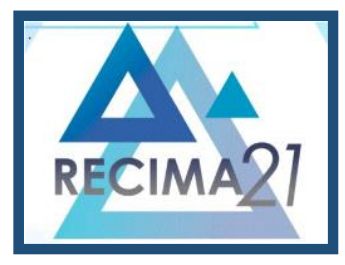

\section{RECIMA21 - REVISTA CIENTÍFICA MULTIDISCIPLINAR}

MODELOS DE TOMADA DE DECISÃO DO CONSUMIDOR, DESTACANDO OS ASPECTOS APLICÁVEIS AOS SERVIÇOS FINANCEIROS E OS QUE REQUEREM ADAPTAÇÃO. Evandro Ferigato

Entende-se que os consumidores realizam um processo complexo ao tomar decisões sobre serviços financeiros, por exemplo, escolhendo opções de planejamento de aposentadoria (Harrison et al., 2006; McKechnie, 1992). O processo de tomada de decisão para serviços financeiros é pouco pesquisado, principalmente para serviços ao consumidor, como planejamento de aposentadoria (Gough \& Sozou, 2005; Harrison et al., 2006). Um objetivo abrangente desta pesquisa é de um contexto de comunicação, para entender melhor como profissionais de marketing e formuladores de políticas podem se comunicar de maneira mais eficaz com consumidores atuais e potenciais de serviços financeiros. No entanto, todos os elementos do mix de marketing podem ser mais bem direcionados com um entendimento aprimorado dos processos de MTDC.

Este artigo analisa os principais Modelos de Tomada de Decisão do Consumidor para identificar os principais componentes, com o objetivo de aplicar os elementos relevantes para formar parte de um novo modelo conceitual de MTDC para serviços financeiros. Uma exploração da pesquisa sobre o comportamento do consumidor em relação aos serviços financeiros apoia o desenvolvimento do modelo. Uma estrutura relevante para entender e pesquisar a tomada de decisões para serviços financeiros facilitará as decisões de marketing no setor, além de fornecer aos formuladores de políticas, informações mais detalhadas sobre a tomada de decisões, a fim de criar auxílios mais adequados à tomada de decisões (Pfeiffer, Riedl \& Rothlauf, 2009), que podem ajudar os consumidores a tomar decisões melhoradas (Milkman, Chugh \& Bazerman, 2009).

Um reexame dos modelos de MTDC está muito atrasado, já que o modelo mais comumente "ensinado" de MTDC (variantes do modelo de McCarthy et al. 1997 discutidas posteriormente neste artigo) agora tem 25 anos. Atualmente, muitas construções de comportamento do consumidor são muito mais bem compreendidas do que há 25 anos e existem escalas robustas e outros instrumentos de medição disponíveis. Por exemplo, o trabalho sobre o construto de reconhecimento de problemas de Bruner \& Pomazal (1993), quando considerado ao lado do trabalho de Oliver (2010), permite uma definição conceitual muito mais articulada de Reconhecimento de Problemas (ou Necessidade de Despertar). A compreensão do marketing de serviços em geral e dos serviços financeiros em particular também avançou bastante nos últimos 25 anos. O campo de comportamento do consumidor atingiu agora um ponto de mudanças.

\section{REFERENCIAL TEÓRICO}

Serão discutidos no referencial teórico os temas abaixo, objetivando em alicerçar a pesquisa:

- Modelos de tomada de decisão do consumidor

- A teoria de Maslow (1954)

- Modelo de Nicósia (1966)

- Modelo de Engel, Kollat e Blackwell (1968)

- Modelo de Howard e Sheth (1969)

- Modelo McCarthy, Perreault e Quester (1997) 


\section{RECIMA21 - REVISTA CIENTÍFICA MULTIDISCIPLINAR}

MODELOS DE TOMADA DE DECISÃO DO CONSUMIDOR, DESTACANDO OS ASPECTOS APLICÁVEIS AOS SERVIÇOS FINANCEIROS E OS QUE REQUEREM ADAPTAÇÃO. Evandro Ferigato

- Modelo de Kotler, (1998)

- Modelo de tomada de decisão do consumidor para serviços financeiros

- Recursos abrangentes do modelo de Relevância para serviços financeiros

\subsection{MODELOS DE TOMADA DE DECISÃO DO CONSUMIDOR}

Os Modelos de Tomada de Decisão do Consumidor (MTDC) vêm se desenvolvendo nos últimos 50 anos e abrangem pesquisas sobre várias construções derivadas dos campos econômico e psicológico.

Segundo Karsaklian (2011, p. 13), "ser consumidor é ser humano. Ser consumidor é alimentar-se, vestir-se, divertir-se, é viver". Essa é uma das definições existentes para essa parte do ser humano, uma parte que é comum a todos nós. De acordo com Richers (1984), tem como característica seus pensamentos e emoções realizados na escolha dos produtos e serviços visando atender seus desejos e satisfações.

A decisão pelo processo de compra não é independente e às vezes não ocorre de forma simples. Para Cobra (2009) tal realização da compra em si, depende de muitos fatores. O processo de decisão de compra diz respeito às etapas realizadas pelo consumidor na sua busca pelo produto satisfatório. "As empresas inteligentes tentam compreender plenamente o processo de decisão de compra dos clientes - todas as suas experiências de aprendizagem, escolha, uso, e inclusive descarte de um produto" (Kotler; Keller, 2006, p. 188).

Muitas vezes a realização deste processo de compra será efetuada apenas por um indivíduo. Para Samara e Morsch (2005), existem seis etapas especificas que o processo de compra seja efetuado:

a) Iniciador: é o indivíduo que primeiro sugere a ideia de compra de determinado produto;

b) Influenciador: é a pessoa cuja opinião ou ponto de vista tem forte peso para que se chegue à decisão final;

c) Decisor: é a pessoa que determina a decisão de comprar;

d) Comprador: é a pessoa que efetivamente realiza a compra;

e) Consumidor (ou usuário): é a pessoa que consome ou utiliza o produto;

f) Avaliador: é a pessoa que julga se o produto é adequado ao uso.

Para Samara e Morsch (2005), é importante reconhecer que o consumidor pode, ocasionalmente, não envolver apenas um indivíduo, mas um grupo de pessoas, e que cada membro poderá ter uma contribuição diferente no processo de compra.

\subsection{A TEORIA DE MASLOW (1954)}

A teoria de Maslow (1954) foi originalmente aplicada como uma teoria geral da motivação psicológica. No entanto, a utilidade de seu modelo teórico foi adotada pelo teórico organizacional, McGregor (1960), que aplicou a teoria de Maslow no local de trabalho (Blackler \& Williams, 1971). E 


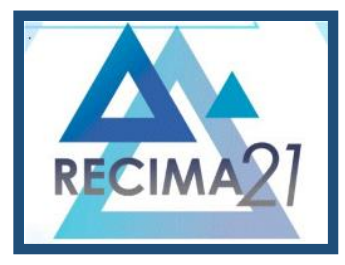

\section{RECIMA21 - REVISTA CIENTÍFICA MULTIDISCIPLINAR}

MODELOS DE TOMADA DE DECISÃO DO CONSUMIDOR, DESTACANDO OS ASPECTOS APLICÁVEIS AOS SERVIÇOS FINANCEIROS E OS QUE REQUEREM ADAPTAÇÃO. Evandro Ferigato

mais tarde, a teoria da "hierarquia de necessidades" foi adaptada e incorporada aplicações em muitas áreas de negócios (Shoura \& Singh, 1998.).

A teoria da hierarquia de necessidades de Maslow é uma teoria simples e intuitiva. Seu modelo é baseado em observações de autoatualização e análise de biografias de figuras conhecidas (Hjelle \&Ziegler, 1976). Os seres humanos teorizados por Maslow têm a tendência inata de buscar auto- atualização (Maslow, 1971). Ele vê que os seres humanos são de natureza benigna. Eckerman (1968) generaliza que a autoatualização para uma pessoa envolve fazer o melhor possível além de criatividade, criatividade e engenhosidade. A autoatualização é a pedra angular da Hierarquia de necessidades de Maslow. Realizar-se é alcançar o pico do potencial de alguém. A teoria de Maslow com seus estudos mudou a maneira do trabalho dos psicólogos tradicionais de estudar pessoas disfuncionais, doenças e o lado negativo do comportamento humano para estudos do lado positivo do ser humano comportamentos. Seu foco é entender pessoas que estão trabalhando para autoatualização, tentativa para aprender como eles pensam e aprender o que os motiva. Seu modelo é mostrar como um homem maduro, pessoa feliz e saudável se comporta. Maslow (1954:14) afirma: “... a saúde não é simplesmente a ausência de desconforto ou mesmo o contrário. Qualquer teoria da motivação que seja digna de atenção deve lidar com as mais altas capacidades da pessoa saudável e forte, bem como com as manobras defensivas dos espíritos aleijados". Quando Maslow viveu em Nova York durante a década de 1930 e 1940, ele conheceu muitos estudiosos europeus importantes, incluindo Alfred Adler, Erich Fromm, Karen Horney, Margaret Mead e Max Wertheimer, fundador da psicologia da Gestalt. Maslow também fez amizade com a famosa antropóloga Ruth Benedict na mesma época. Maslow foi muito inspirado por Ruth Benedict e Max Wertheimer, a quem ele admirava tanto profissionalmente e pessoalmente. Ele iniciou seu estudo informal de pessoas saudáveis, observando-as, fazendo anotações e tentando analisar o que os tornou seres humanos tão destacados (Hergenhahn, 2005). Além de estudar seus amigos e conhecidos pessoais, os grupos de pessoas selecionadas de Maslow também incluíam figuras vivas e mortas como Thomas Jefferson, Albert Einstein, Eleanor Roosevelt, BenjaminFranklin, Thomas Eakins e Walt Whitman, entre outros. No entanto, os sujeitos de Maslow compartilharam uma característica comum de que todos eles mostraram evidências consideráveis de autorrealização (Hjelle \& Ziegler, 1976).Todos eram indivíduos psicologicamente saudáveis pela definição de Maslow. Seu estudo dessas pessoas serve como base para a pesquisa vitalícia de Maslow saúde psicológica e potencial humano.

Figura 1: Pirâmide de necessidades de Maslow. 


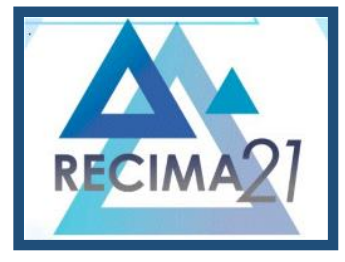

\section{RECIMA21 - REVISTA CIENTÍFICA MULTIDISCIPLINAR}

MODELOS DE TOMADA DE DECISÃO DO CONSUMIDOR, DESTACANDO OS ASPECTOS APLICÁVEIS AOS SERVIÇOS FINANCEIROS E OS QUE REQUEREM ADAPTAÇÃO. Evandro Ferigato

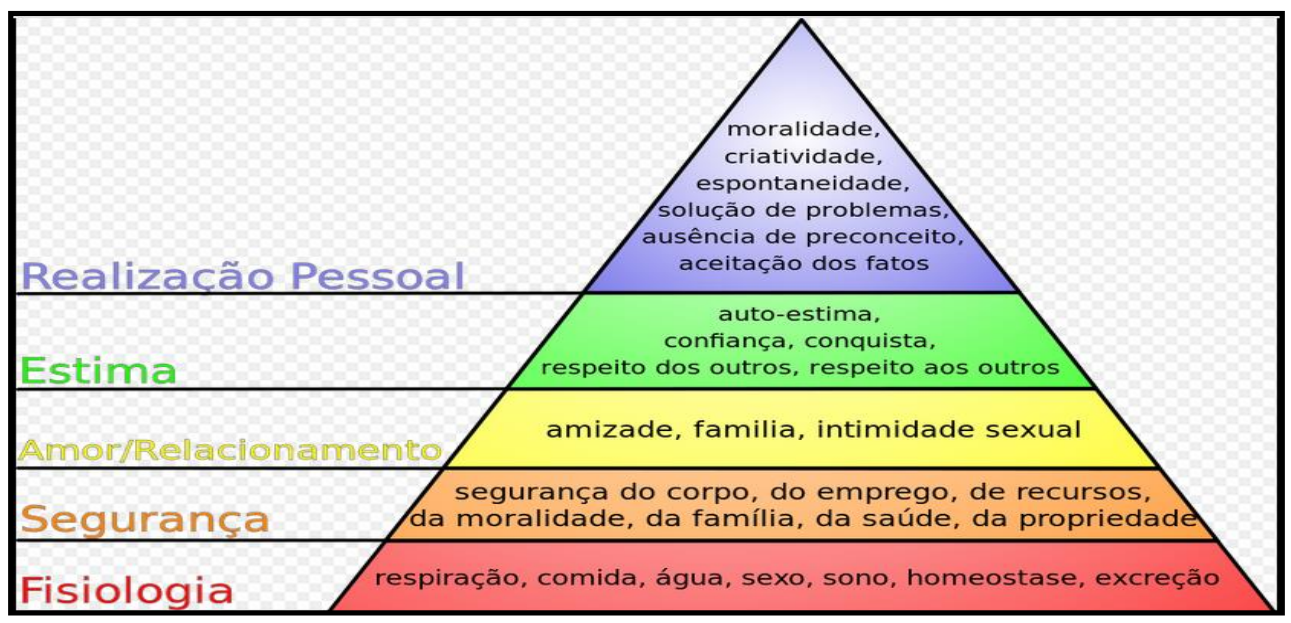

Fonte: Adaptado Robbins, 2002.

\subsection{MODELO DE NICÓSIA (1966)}

O modelo de comportamento do comprador de Nicósia (Nicósia, 1966) é creditado como o primeiro modelo abrangente de comportamento do comprador (por exemplo, ver Jones, Shaw \& McClean, 2011). O modelo de Nicósia consiste em quatro 'campos', começando com a comunicação de informações para afetar a atitude do consumidor (influenciada pelos atributos da empresa e dos consumidores, principalmente predisposições ao consumidor), seguida por um processo de busca e avaliação, uma decisão e resultados em termos de comportamento, consumo, armazenamento, experiência e feedback. A formulação do processo por Nicósia para incluir um ciclo iterativo ou de recompra é importante para o desenvolvimento da estrutura conceitual e muito relevante para o contexto dos serviços. Em serviços financeiros, em particular, os consumidores podem comprar uma ampla gama de produtos (por exemplo, serviços bancários, fornecedor ao longo de vários anos. Além disso, pode haver altos riscos psicológicos e monetários associados à mudança de empresas ou produtos em serviços financeiros e, portanto, muitas vezes percebidas barreiras à mudança. Portanto, é necessário um ciclo de recompra ou feedback em qualquer MTDC para serviços financeiros.

No entanto, uma grande limitação do modelo de Nicósia é que ele é da perspectiva do profissional de marketing e não do consumidor, com atividades de consumidores definidas de maneira muito ampla. Também tem havido pouco trabalho empírico para apoiar o modelo, enquanto há muito trabalho empírico para sugerir que os relacionamentos descritos no modelo não são de fato válidos (Tuck, 1976).

\subsection{MODELO DE ENGEL, KOLLAT E BLACKWELL (1968)}

O modelo de Nicósia foi ajustado por Engel, Kollat e Blackwell no final dos anos 1960 (Engel et al., 1968). Um dos pontos fortes do modelo revisado é o loop de feedback ou 'pesquisa', que permite iterações de tomada de decisão parcial. Por exemplo, um consumidor pode prosseguir além 


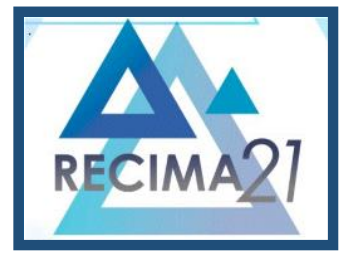

\section{RECIMA21 - REVISTA CIENTÍFICA MULTIDISCIPLINAR}

MODELOS DE TOMADA DE DECISÃO DO CONSUMIDOR, DESTACANDO OS ASPECTOS APLICÁVEIS AOS SERVIÇOS FINANCEIROS E OS QUE REQUEREM ADAPTAÇÃO. Evandro Ferigato

das entradas para chegar ao estágio de reconhecimento de problemas necessário, executar uma pesquisa externa por informações e, por algum motivo, optar por não concluir o processo de tomada de decisão. Embora o processo de tomada de decisão possa ser realizado, pode não haver intenção de compra e, portanto, o processo de decisão pode ser interrompido ou adiado a qualquer momento, fornecendo feedback para uso como insumos na próxima vez que surgir uma necessidade. Um exemplo disso é o estereótipo de "vitrine", ou no contexto de serviços financeiros, participar de um seminário de investimentos sem necessariamente ter a intenção de investir no curto prazo. A realização do processo pode ser considerada um teste para recuperação posterior, ou o processo interrompido por algo mais importante, ou o consumidor simplesmente não tem capacidade para realizar o restante do processo.

Embora contenha muitos ciclos de feedback e interações, esse modelo de fato apresenta um processo mais linear de tomada de decisão do consumidor. No cerne deste modelo, há um claro fluxo de tarefas, que descreve um processo ideal de tomada de decisão, em que o indivíduo sabe que existe um problema com uma solução para o consumidor, mas tem pouco 'outro conhecimento' da área. O indivíduo então realiza, em ordem, uma busca por informações relevantes sobre soluções, avaliação das alternativas em relação a um conjunto de critérios, escolha de uma e execução das tarefas de compra dos produtos.

A natureza linear do modelo é uma das principais fontes de crítica, pois se reconhece que os elementos do processo de tomada de decisão do comprador não ocorrem necessariamente em uma sequência definida (Brinberg \& Lutz, 1986) e alguns podem de fato ocorrer simultaneamente (Phillips \& Bradshaw, 1993). Essa é uma distinção importante para este artigo, porque, embora seja confortável pensar que, quando uma solução é procurada, uma pessoa procura informações, cria uma lista de critérios pelos quais comparar as diferentes opções e depois avalia-las como melhor eles podem, de fato, não se encaixa no tipo de decisão tomada no atual mercado de serviços financeiros. Isso ocorre porque o nível de outras influências conhecidas e o escopo ou tamanho do processo de tomada de decisão podem ser mais complicados ou substancialmente menos. Assim, algumas das variáveis podem ser retiradas de sua ordem tradicional e outras podem ser ignoradas por completo - especialmente com compras repetidas ou com pouca importância.

Outra limitação do modelo é a suposição implícita de que os consumidores têm a capacidade de avaliar as alternativas e fazer um julgamento racional sobre a alternativa mais adequada. Como muitos serviços, os serviços financeiros têm qualidades de credibilidade com muitas variáveis moderadoras, o que dificulta a avaliação dos consumidores, mesmo após a compra (Chung-Herrera, 2007; Ennew, 1993; Harrison, 2003; Harrison et al., 2006; McKechnie, 1992). Por exemplo, os consumidores têm dificuldade em avaliar os conselhos fornecidos após uma reunião com um planejador financeiro. Frequentemente um A avaliação desse valor requer custos adicionais, como um investimento de fundos de acordo com o conselho (Eisingerich \& Bell, 2007; Harrison et al., 


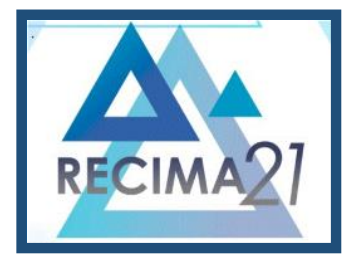

\section{RECIMA21 - REVISTA CIENTÍFICA MULTIDISCIPLINAR}

MODELOS DE TOMADA DE DECISÃO DO CONSUMIDOR, DESTACANDO OS ASPECTOS APLICÁVEIS AOS SERVIÇOS FINANCEIROS E OS QUE REQUEREM ADAPTAÇÃO. Evandro Ferigato

2006); portanto, uma "compra" é necessária logo no início do processo, modelos de MTDC centrados em mercadorias.

Bray (2008) resume críticas gerais ao modelo, observando que sua abordagem mecanicista não se aplica bem a contextos variados de tomada de decisão. Ele também observa que as variáveis ambientais e de consumo, e seus mecanismos para influenciar a tomada de decisão, não foram claramente especificados (Bray, 2008). Essas fraquezas no modelo são particularmente relevantes para os serviços financeiros: a natureza pessoal de muitos serviços financeiros significa que as variáveis do consumidor são críticas e é bem sabido que o ambiente de serviço tem um grande impacto na tomada de decisões, principalmente na ausência de outros fatores tangíveis, dicas de qualidade.

\subsection{MODELO DE HOWARD E SHETH (1969)}

O modelo de Howard e Sheth (1969) apresentou um avanço na época devido a um nível aprimorado de especificidade em termos das relações entre variáveis, por exemplo, o modelo observa não apenas que atitude influencia a compra, mas também sua intenção é uma variável moderadora (Hunt \& Pappas, 1972). O modelo também é notável por incluir uma ampla gama de insumos no processo em termos de variáveis de marketing e influências sociais, o que é um passo importante para os atuais modelos de insumo-processo-produto.

O modelo representava um fluxo de informações que se movia por quatro componentes principais: 1) entradas (estímulos de marketing e sociais), 2) construções perceptivas (atenção e busca de informações), 3) construções de aprendizagem (motivos, critérios de escolha, compreensão da marca, levando a atitude, confiança, intenção e satisfação) e 4) resultados (compra, intenção, atitude, compreensão e atenção à marca) (Howard \& Sheth, 1969). Um quinto elemento, variáveis exógenas (importância da compra; histórico do consumidor, grupos de referência, traços de personalidade; tempo disponível e status financeiro) foram incluídos como influência nos constructos perceptivos e de aprendizado, em vez de fazer parte do próprio fluxo de informações (Howard \& Sheth, 1969).

Por ser mais abrangente, o modelo de Howard e Sheth (1969) certamente alcança uma noção da complexidade do processo, com múltiplas variáveis com múltiplas relações com processos internos e acionadores externos e fontes de informação. Foram introduzidos conceitos como formação de atitude, predisposição e tempo, além de um senso abrangente de construções perceptivas e de aprendizagem. Paradoxalmente, a complexidade do modelo de Howard e Sheth também é uma de suas deficiências.

Deve-se notar que o teste de confirmação inicial do modelo de Howard e Sheth (1969) de Farley e Ring (1970) apresentou resultados altamente desfavoráveis e não confirmatórios. Os testes iniciais pressionaram os dados e pediram uma coleta e procedimentos aprimorados antes que as construções e os relacionamentos reivindicados por Howard e Sheth (1969) pudessem ser 


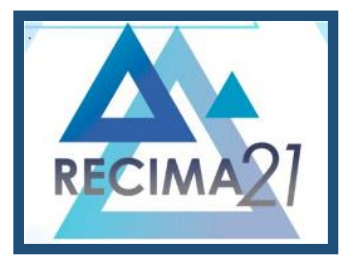

\section{RECIMA21 - REVISTA CIENTÍFICA MULTIDISCIPLINAR}

MODELOS DE TOMADA DE DECISÃO DO CONSUMIDOR, DESTACANDO OS ASPECTOS APLICÁVEIS AOS SERVIÇOS FINANCEIROS E OS QUE REQUEREM ADAPTAÇÃO. Evandro Ferigato

confirmados. No entanto, os testes de Farley e Ring tornaram-se objeto de crítica em si, e levaram ao debate sobre os testes de tais modelos em geral (Hunt \& Pappas, 1972; Lutz \& Resek, 1972; Taylor \& Gutman, 1974). Em 1972, muitos dos construtos dentro dos modelos de MTDC não haviam sido extensivamente explorados (por exemplo, o paradigma de desconfirmação relevante para o construto de satisfação no modelo originado apenas no artigo de Oliver (1980)) e, portanto, houve dificuldades consideráveis na operacionalização de modelos teóricos amplos. Havia um reconhecimento evidente na literatura de que um modelo abrangente poderia fornecer valor conceitualmente, mesmo que não fosse possível testá-lo completamente naquele momento (Taylor e Gutman, 1974). Isso pode ser visto como um ponto de virada no desenvolvimento de modelos de MTDC, pois enquanto o modelo de Nicósia foi formulado a partir de fórmulas explícitas e mantém algum nível de rigor estatístico, havia um reconhecimento evidente na literatura de que um modelo abrangente poderia fornecer valor conceitualmente, mesmo que não fosse possível testá-lo completamente naquele momento (Taylor e Gutman, 1974). O modelo de Howard e Sheth (1969) inicia a tendência de comportamento do consumidor, passando de modelos matemáticos para modelos conceituais.

Embora sua importância na evolução dos modelos de MTDC seja clara, o modelo de Howard e Sheth sofre de limitações conceituais. As evidências sugerem que os consumidores nem sempre seguem todo o caminho do modelo, e o modelo é muito complicado para compras de rotina (Olshavsky \& Granbois, 1979). Além disso, há problemas com a representação do modelo de consumidores que se deslocam de uma etapa para outra de maneira linear e, portanto, o modelo está sujeito às mesmas críticas de Engel et al.

\subsection{MODELO DE MCCARTHY, PERREAULT E QUESTER (1997)}

O modelo McCarthy, Perreault e Quester (1997) de tomada de decisão do consumidor, ou uma variante dele, aparece na maioria dos casos, em livros introdutórios do século sobre marketing e comportamento do consumidor (por exemplo, Kotler e Armstrong, 2010; Neal, Quester e Hawkins, 2006). Essencialmente, McCarthy et al. modelo é uma modificação do Engel et al. modelo com algumas pequenas alterações e esclarecimentos. Por exemplo, McCarthy acrescenta o conceito de critério de escolha, que é uma importante descompactação da tarefa de avaliação, pois reconhece que a tarefa de estabelecer critérios é bem diferente de avaliar as alternativas. O McCarthy et al. (1997) conseguiu agrupar construções semelhantes de uma forma com simplicidade lógica, mantendo-se abrangente. No entanto, exibe alguns dos pontos fracos comuns aos modelos que o precederam, como: representando um processo linear; representando uma influência limitada e contra intuitiva de social e variáveis situacionais (são mostrados como impactando apenas precisa querer conscientização); e não indicando claramente a maneira pelas quais variáveis psicológicas influenciam o processo. Como observado anteriormente, esses problemas são significativos no contexto de serviços financeiros. 


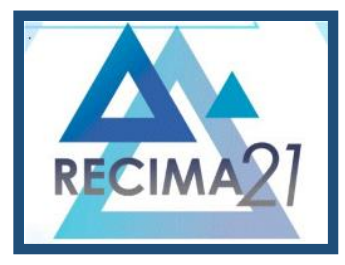

\section{RECIMA21 - REVISTA CIENTÍFICA MULTIDISCIPLINAR}

MODELOS DE TOMADA DE DECISÃO DO CONSUMIDOR, DESTACANDO OS ASPECTOS APLICÁVEIS AOS SERVIÇOS FINANCEIROS E OS QUE REQUEREM ADAPTAÇÃO. Evandro Ferigato

Vale a pena reiterar que a pesquisa apoia nossa alegação de que um modelo linear não é adequado para serviços financeiros: observou-se que as decisões sobre serviços financeiros podem durar muitos anos com várias tentativas fracassadas de compra (Harrison et al., 2006; McKechnie, 1992; McKechnie e Harrison, 1995). Os consumidores também podem comprar sem intenção de compra (Bloch \& Richins, 1983; Bloch, Sherrell e Ridgway, 1986; Earl \& Potts, 2000). Isso implica que os consumidores podem não apenas parar no meio da decisão, mas também fazer uma pausa por longos períodos (Greenleaf \& Lehmann, 1995). Além disso, o conceito de consumidores que se deslocam em um processo linear por meio da tomada de decisão é discutível com os achados de que alguns processos de tomada de decisão envolvem triagem, faseamento e estágios múltiplos (Aribarg \& Foutz, 2009; Payne, Bettman e Johnson, 1988).

\subsection{MODELO DE KOTLER, (1998)}

Segundo Kotler e Keller (2006), uma vez que o propósito do marketing centra-se em atender e satisfazer às necessidades e desejos dos consumidores torna-se fundamental conhecer o seu comportamento de compra.

São inúmeras situações externas e internas que favorecem na Tomada do Processo de Decisão do Consumidor (Figura 1). Churchill e Peter (2005), confirmam que um dos meios mais importantes pelos quais uma sociedade influencia o comportamento dos indivíduos é pela sua cultura.

Figura 2 - Fatores Influenciadores na Etapa de Compra

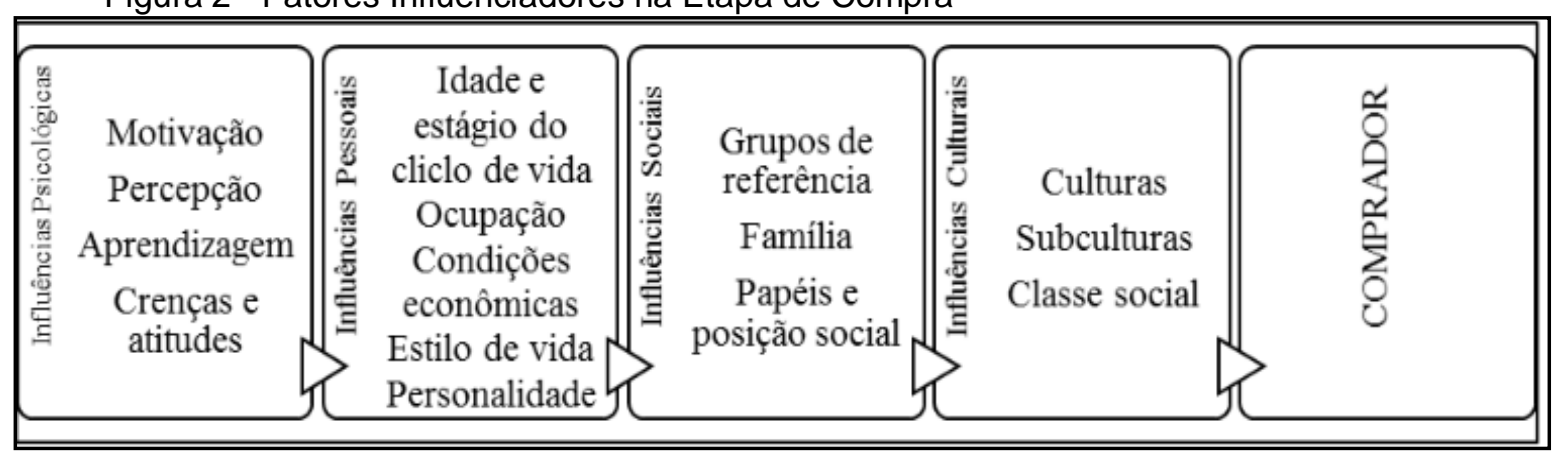

Fonte: Kotler (1998, p. 163).

O Modelo de Cinco Etapas é evidenciado na sua utilização por Kotler e Keller (2006) a fim de confirmar as fases percorridas do consumidor na sua decisão de compra. "O consumidor passa por cinco etapas: reconhecimento do problema, busca de informações, avaliação de alternativas, decisão de compra e comportamento pós-compra" (KOTLER; KELLER, 2006, p. 189). Essas etapas podem ser ilustradas como visto na Figura 3. 


\section{RECIMA21 - REVISTA CIENTÍFICA MULTIDISCIPLINAR}

MODELOS DE TOMADA DE DECISÃO DO CONSUMIDOR, DESTACANDO OS ASPECTOS APLICÁVEIS AOS SERVIÇOS FINANCEIROS E OS QUE REQUEREM ADAPTAÇÃO. Evandro Ferigato

Figura 3 - Modelo utilizado pelos consumidores em Cinco Etapas

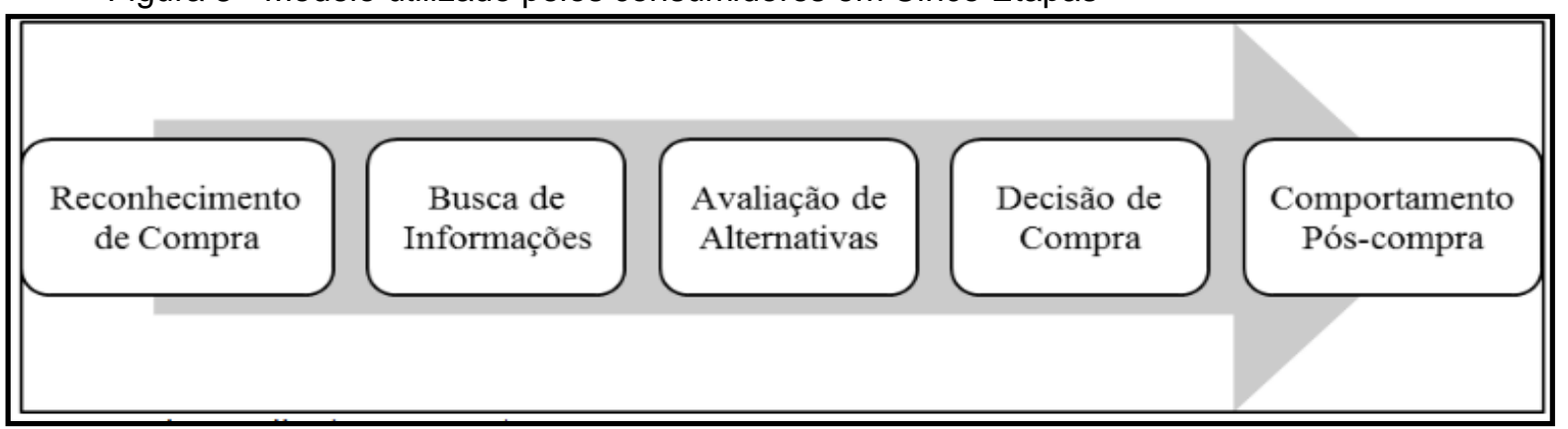

Fonte: Kotler e Keller (2006, p. 189).

\subsection{MODELO DE TOMADA DE DECISÃO DO CONSUMIDOR PARA SERVIÇOS FINANCEIROS}

Um modelo conceitual para consumidores que tomam decisões sobre serviços financeiros é apresentado na Figura 3. Embora alguns fundamentos da tomada de decisões se apliquem a todos os tipos de compras, as circunstâncias específicas para produtos de alta credibilidade, como serviços financeiros, exigem uma reformulação das variáveis e processos. Portanto, o modelo usa alguns elementos dos modelos anteriores de tomada de decisão do consumidor, mas oferece mudanças significativas relevantes para as características particulares dos serviços financeiros. Existem dez componentes no novo modelo e eles são amplamente agrupados em três categorias: entradas, processos e resultados. Um resumo abrangente das variáveis reformuladas é apresentado abaixo.

Figura 4: Estrutura conceitual da tomada de decisão do consumidor para serviços financeiros

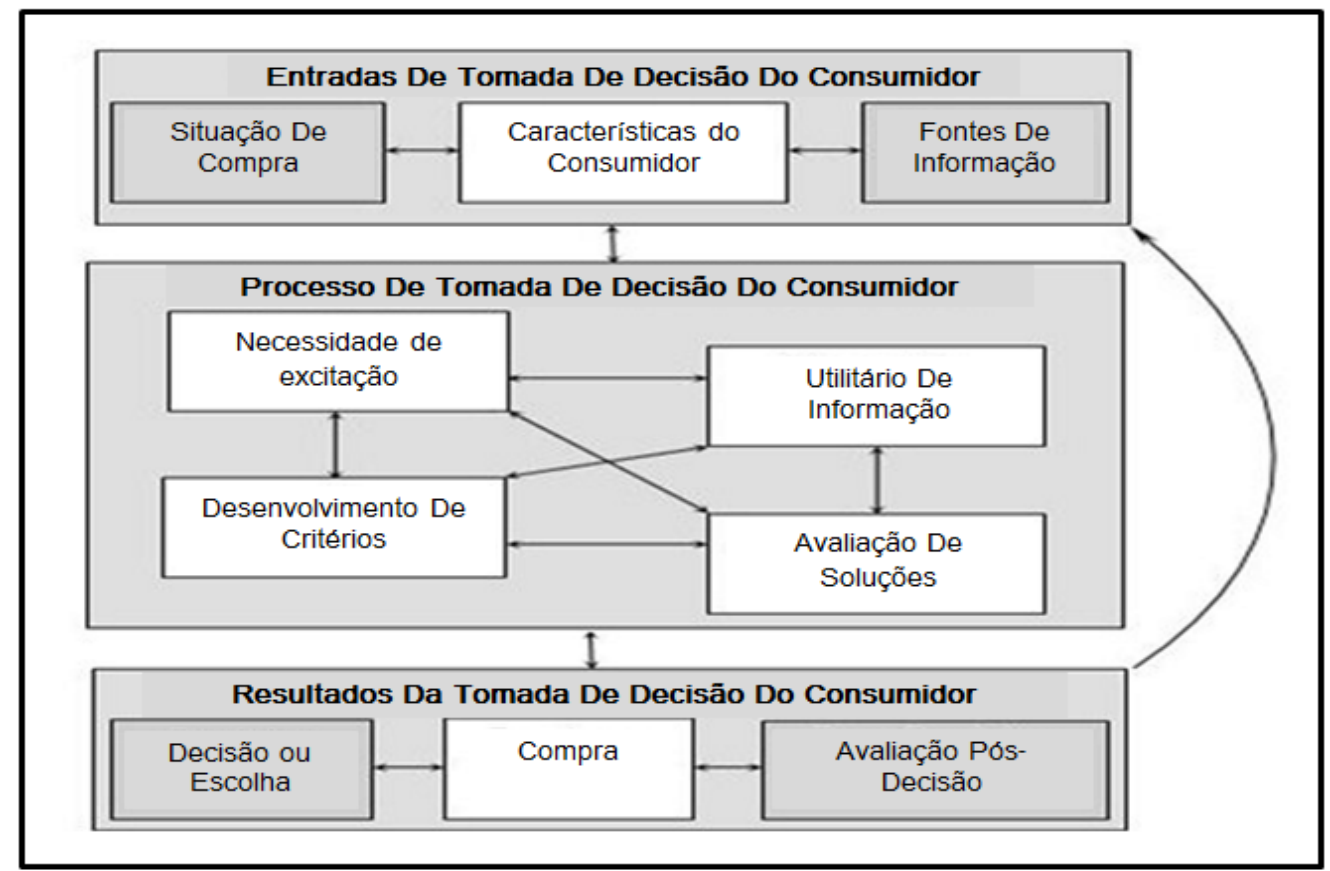

Fonte: Adaptado de Blackwell, Miniard e Engel (2005, p. 73). 


\section{RECIMA21 - REVISTA CIENTÍFICA MULTIDISCIPLINAR}

MODELOS DE TOMADA DE DECISÃO DO CONSUMIDOR, DESTACANDO OS ASPECTOS APLICÁVEIS AOS SERVIÇOS FINANCEIROS E OS QUE REQUEREM ADAPTAÇÃO. Evandro Ferigato

Entradas para tomada de decisão do consumidor: O primeiro componente do novo modelo são as entradas, compostos pela situação da compra, características do consumidor e fontes de informação. Situação da compra: A compra é definida como o ímpeto ou fatores externos que podem levar o consumidor a compreender a diferença entre o estado desejado e o atual. Esta é uma entrada para o sistema de tomada de decisão porque a situação da compra inclui variáveis contextuais e ambientais, bem como o objetivo da compra. As construções que se encaixam nessa parte do modelo incluem envolvimento (com a categoria do produto), o tipo de produto financeiro que está sendo considerado e outras variáveis contextuais, incluindo eventos significativos da vida, como casamento e aposentadoria. Há muito tempo se aceita que os eventos da vida são uma grande influência no comportamento do consumo em geral (por exemplo, Andreasen, 1984; Belk, 1988) e em serviços financeiros especificamente (Lazarus \& Folkman, 1984; Mergenhagen, 1995; Schewe \& Meredith, 1994).

Também é sabido que o tipo de produto considerado influencia o processo de tomada de decisão, e isso é igualmente verdade para os serviços financeiros (Rickwood \& White, 2009). Por exemplo, McColl-Kennedy e Fetter (1999) descobriram que o tipo de busca de informações conduzida variava dependendo de um serviço ser mais ou menos direcionado por pessoas.

Características do Consumidor: Para esse modelo são uma fusão das duas entradas do modelo McCarthy (1997) de influências psicológicas e sociais, com a adição dos principais indicadores demográficos. As variáveis sob consideração nesta seção são ampliadas para incluir influências pessoais do consumidor, bem como psicológicas ou sociais. Os sub elementos frequentemente medidos neste construto incluem, entre outros, estilos de vida, motivos, atitudes, personalidade, envolvimento de atitudes, memória, conhecimento / aprendizagem, idade, faixa etária, renda, objetivos e outras variáveis demográficas e culturais. A influência de tais variáveis na tomada de decisão do consumidor foi objeto de extensa pesquisa ao longo de muitos anos e pode ser encontrada em qualquer livro de comportamento do consumidor, bem como na literatura psicológica sobre a tomada de decisão do consumidor (por exemplo, 2009).

Fontes de informação: Essa variável refere-se a informações de organizações e fontes interpessoais como uma entrada para o processo de tomada de decisão. (As informações também são abordadas na seção de processo do modelo, discutida abaixo). Isso é reconhecido por McCathy et al. (1997) em seus dois componentes periféricos de marketing misturas e todos os outros estímulos. No caso dos serviços, o mix de marketing inclui evidências físicas, pessoas e processos (Bitner \& Booms, 1981), bem como o preço, local, produto e promoções tradicionais, os quais podem transmitir informações ao consumidor. Por exemplo, a peça seminal de Kotler sobre atmosferas observa como a atmosfera é uma "'linguagem silenciosa' nas comunicações" (1973, p. 48) e o trabalho de Bitner (1992) na paisagem de serviços esclarece os muitos aspectos de um ambiente de serviço que podem impactar as percepções dos consumidores. A importância das informações de fontes pessoais para as decisões dos consumidores relacionadas aos serviços (principalmente 


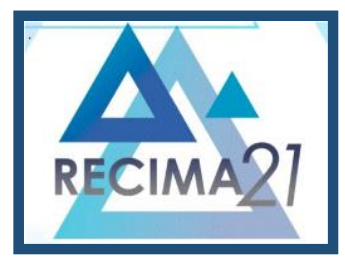

\section{RECIMA21 - REVISTA CIENTÍFICA MULTIDISCIPLINAR}

MODELOS DE TOMADA DE DECISÃO DO CONSUMIDOR, DESTACANDO OS ASPECTOS APLICÁVEIS AOS SERVIÇOS FINANCEIROS E OS QUE REQUEREM ADAPTAÇÃO. Evandro Ferigato

aquelas com alta qualidade de credibilidade) também é reconhecida há muitos anos (King \& Hill, 1997; Murray, 1991).

O novo modelo mostra mais claramente do que os modelos anteriores que as informações no ambiente interagem com a situação da compra e as características do consumidor, para influenciar a excitação da necessidade, em vez de ter um relacionamento linear. Por exemplo, uma mensagem lembrando aos consumidores prazos de impostos, taxas de juros ou uma nova emissão de ações pode ter uma influência direta na instigação de um processo de decisão do consumidor.

Além disso, a construção de informações em um contexto de serviços financeiros é mais complicada porque as informações em si são frequentemente vistas como indisponíveis ou dispendiosas para obter, e os consumidores nem sempre têm as habilidades ou conhecimentos para entender as informações (McKechnie, 1992). Essas dificuldades com a acessibilidade e compreensão das informações estão claramente relacionadas ao construto anterior 'características do consumidor' e também estão relacionadas ao construto 'utilidade da informação' discutido como parte do elemento de processo do modelo abaixo.

Processos de tomada de decisão do consumidor: A segunda parte principal do modelo de tomada de decisão proposto para os serviços ao consumidor são os processos, incluindo despertar necessidade, utilidade da informação, desenvolvimento de critérios e avaliação de alternativas.

Necessidade de excitação: É uma medida para que o indivíduo reconheça a necessidade de uma solução e escolhe ativar o restante do processo ou, alternativamente, a necessidade permanece latente e o processo é parcial. Os conceitos que sustentam a necessidade de excitação foram estudados com mais detalhes (ver Bruner \& Pomazal, 1993 para uma articulação aprofundada do processo de excitação de necessidade).

Esse construto foi reformulado a partir do tradicional 'Reconhecimento de Problemas' para representar de maneira mais adequada o estado sentido ou os componentes afetivos que foram investigados com robustez desde sua aparição no modelo de Engel et al (1968), bem como pelos teóricos fundadores Cannon (1932), e Maslow (1943, 1970). Embora este seja um processo simples para muitos bens físicos, no caso de serviços financeiros, é menos comum que um indivíduo reconheça simultaneamente que existe um problema / oportunidade financeira e a categoria de serviço específica a ser usada para resolvê-lo. Mais frequentemente, é um grande período de latência, ou "reconhecimento sem ação", que precede a adoção de um serviço financeiro (Greenleaf \& Lehmann, 1995).

Este é o primeiro componente processual do processo de tomada de decisão e é visto como o gatilho para a continuação do processo (Bruner \& Pomazal, 1993). No contexto deste artigo, foi levantado acima dos outros componentes processuais para indicar a ordem estabelecida pelos modelos anteriores, no entanto, relações recíprocas entre todas as outras variáveis processuais estão presentes, o que é um avanço em relação aos modelos anteriores. Indicando, por exemplo, que as fontes de informação como uma entrada podem reagir com o componente do utilitário de 


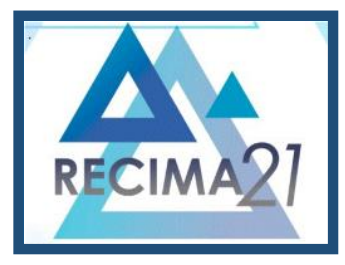

\section{RECIMA21 - REVISTA CIENTÍFICA MULTIDISCIPLINAR}

MODELOS DE TOMADA DE DECISÃO DO CONSUMIDOR, DESTACANDO OS ASPECTOS APLICÁVEIS AOS SERVIÇOS FINANCEIROS E OS QUE REQUEREM ADAPTAÇÃO. Evandro Ferigato

informações para causar uma excitação em necessidade enquanto, por exemplo, assiste a um item de notícias sobre opções de investimento.

Utilitário de Informações: O utilitário de informações pode ser definido como a coleta, processamento e uso de informações, de qualquer fonte, para auxiliar na resolução do problema / oportunidade. Essa variável de utilidade da informação no processo de tomada de decisão é distinta das fontes de informação que podem estimular o início do processo de tomada de decisão. 0 utilitário de informações é um pouco menor do que o necessário, mas é mais alto do que as outras variáveis na seção de processos do modelo para indicar que às vezes (mas nem sempre) ocorre antes dos outros estágios (conforme sugerido nos modelos tradicionais de MTDC). O utilitário de informações refere-se à necessidade de informações de fontes externas e internas do consumidor. Fontes externas incluem comunicações de marketing e fontes interpessoais, enquanto fontes internas incluem memória e aprendizado, conhecimento subjetivo, experiência e conhecimento.

A interação entre a utilidade da informação e os outros processos é uma parte importante do novo modelo - é claro que, à medida que o consumidor coleta e utilizam informações, seu crescente conhecimento também pode influenciar sua concepção de como avaliar suas escolhas e a avaliação. (Bruner, 1986, 1987). Por exemplo, na escolha de um consultor financeiro, um consumidor pode ler que um consultor local tem uma qualificação específica e isso pode influenciar a avaliação de outros consultores em potencial. A qualidade das informações disponíveis em certas instituições de serviços financeiros e a maneira como as informações são fornecidas também podem ter uma forte influência na avaliação do serviço, dada a natureza do serviço com base em informações e a necessidade de sugestões do consumidor para ajudá-lo na avaliação da qualidade do serviço.

Além disso, o conceito de utilidade aqui é projetado para refletir que os consumidores julgam inerentemente $o$ valor percebido e os custos associados à coleta e às expectativas de informações (Wilton \& Myers, 1986). O trabalho seminal de Simon $(1955,1957)$ observa que os consumidores agem apenas com racionalidade limitada, capacidade limitada e que não procuram necessariamente todas as alternativas. Além disso, o processamento de informações como capacidade do consumidor constitui uma entrada para o processo de tomada de decisão, assim como a experiência e o conhecimento. Embora os consumidores procurem inerentemente informações para reduzir riscos percebidos em compras complexas, como serviços financeiros (Mitra, Reiss \& Capella, 1999), eles também podem perceber que as informações não estão disponíveis ou estão disponíveis a um custo que eles não desejam pagar. Também é concebível que o consumidor considere que as informações disponíveis sejam apresentadas de uma maneira difícil de entender, ou que o consumidor percebe o custo (tempo / oportunidade) de 'aprender' a entender as diferentes alternativas é grande demais para ser um empreendimento viável. Características do consumidor e fontes de informação influenciam claramente o utilitário de informações que o consumidor experimenta, além de influenciar os outros elementos do processo. Essa relação não foi claramente representada nos modelos anteriores. 


\section{RECIMA21 - REVISTA CIENTÍFICA MULTIDISCIPLINAR}

MODELOS DE TOMADA DE DECISÃO DO CONSUMIDOR, DESTACANDO OS ASPECTOS APLICÁVEIS AOS SERVIÇOS FINANCEIROS E OS QUE REQUEREM ADAPTAÇÃO. Evandro Ferigato

Desenvolvimento de critérios: O desenvolvimento de critérios para avaliação situa-se entre a utilidade da informação e a aplicação dos critérios nas opções de avaliação. O desenvolvimento de critérios geralmente não é uma construção separada nos modelos tradicionais de MTDC, mas esse componente é relevante porque define os limites da decisão (J. Lee e Marlowe, 1999). O componente de desenvolvimento de critérios do modelo compreende uma consideração preliminar que leva à formação de um conjunto evocado e, em conjunto com isso, o desenvolvimento dos critérios de decisão que serão posteriormente utilizados para avaliar possíveis soluções oferecidas pelo conjunto evocado.

A maioria das decisões é truncada para incluir apenas um pequeno conjunto evocado de alternativas (Howard \& Sheth, 1969), algumas vezes referido como conjunto de considerações (Hauser e Wernerfelt, 1990). O desenvolvimento do conjunto evocado requer uma pesquisa informal de informações, que é distinta da avaliação mais intensiva após a formação do conjunto evocado (Hauser e Wernerfelt, 1990). (Veja Laroche, Kim, e Matsui (2003) para um resumo útil da literatura relativa à formação de conjuntos evocados). Pesquisas sugerem que conjuntos evocados para serviços são, em média, menores do que para bens (Turley e LeBlanc, 1993). A partir do trabalho de Wirtz e Mattila (2003) sobre serviços profissionais no setor de saúde, sabemos que quando os consumidores têm conhecimento menos objetivo e relevante para uma decisão de compra, eles tendem a ter um conjunto evocado menor, porque aqueles com menos conhecimento do produto o encontram mais difícil distinguir entre alternativas. A natureza intangível dos serviços significa que os consumidores frequentemente enfrentam uma escassez de informações relevantes que podem compreender e basear avaliações (King \& Hill, 1997), e isso certamente é verdade para muitos serviços financeiros.

O desenvolvimento de critérios avaliativos é relevante para as decisões de compra de serviços financeiros, principalmente devido à complexidade percebida de alguns dos produtos, e os consumidores podem não ser capazes de apreciar as diferenças entre os provedores de serviços financeiros disponíveis. A tomada de decisão para serviços financeiros também é complicada pelo fato de que uma gama de produtos diversos pode atingir objetivos muito semelhantes. Por exemplo, uma estratégia de investimento completamente substituível poderia usar, planejamento financeiro, gerenciamento de fundos, corretagem de ações, empréstimos à habitação, aposentadoria ou uma combinação de tudo isso por meio de aposentadoria auto gerenciada (dependendo do contexto). Parece que os consumidores tendem a usar um número menor de recursos importantes para avaliar serviços do que em bens físicos (Turley \& LeBlanc,1993), e a complexidade das decisões poderia explicar isso.

Avaliação de soluções: Fica abaixo do desenvolvimento dos critérios e é anterior aos resultados no modelo. Mecanismos de avaliação são heurísticas ou regras de decisão (Plous, 1993), que são essencialmente técnicas usadas para avaliar as alternativas apresentadas a partir dos componentes procedimentais anteriores. 


\section{RECIMA21 - REVISTA CIENTÍFICA MULTIDISCIPLINAR}

MODELOS DE TOMADA DE DECISÃO DO CONSUMIDOR, DESTACANDO OS ASPECTOS APLICÁVEIS AOS SERVIÇOS FINANCEIROS E OS QUE REQUEREM ADAPTAÇÃO. Evandro Ferigato

O processo de decisão: Os consumidores diferem nas regras que eles usam para avaliar mercadorias (Bettman, Johnson \& Payne, 1991), permitindo a comparação de técnicas por grupos. As técnicas usadas para avaliar serviços financeiros alternativos podem ser derivadas da literatura heurística. Observou-se por Plous (1993) e Olshavsky e Granbois (1979) que um 'conceito de processamento contingente' precisava ser ampliado para incluir heurísticas como agência, conformidade, imitação e recomendações. Diferentes níveis de excitação das necessidades podem resultar no uso de diferentes regras de decisão, o que é importante observar ao comercializar serviços.

A avaliação de soluções no modelo inclui produtos substitutos e categorias de produtos, bem como a escolha da marca. Essa é uma expansão do construto a partir das classificações restritas apresentadas em alguns modelos, como Howard e Sheth (1969), onde a avaliação da escolha da marca era o objetivo final. As estruturas inerentes ao mercado de serviços financeiros e a substituibilidade dos serviços tornam superficial a escolha da marca, pois exige que a escolha da categoria do produto seja realizada antes do processo de tomada de decisão. Embora isso possa ficar claro em outras categorias de produtos ou serviços, os serviços financeiros podem ter alta capacidade de substituição, por exemplo, poucos consumidores observam a diferença entre gerentes de fundos e planejadores financeiros, cuja decisão geralmente é tomada ao mesmo tempo em que a escolha da marca / produto (Black, Lockett, Ennew, Winklhofer)

Pesquisas recentes sugerem que a necessidade de excitação e avaliação de alternativas pode ser a mais proeminente das variáveis de tomada de decisão, e que muitos consumidores confiam amplamente em conhecimento prévio e em critérios pré-concebidos ao tomar uma decisão (Mata \& Nunes, 2010; Yoon et al. 2009). Isso poderia tornar a excitação da necessidade e o método de avaliação por meio de uma heurística os componentes mais influentes do processo de tomada de decisão.

Resultados da tomada de decisão do consumidor: $O$ terceiro componente do modelo conceitual são os resultados, incluindo a decisão, compra e avaliação pós-decisão.

Decisão ou escolha: Uma decisão é o resultado imediato dos elementos do processo de tomada de decisão. A decisão é considerada separada da compra devido à separação das atividades e ao fato de que a decisão não necessariamente leva à compra. Por exemplo, um consumidor pode não ter os meios financeiros para poder concluir a transação; uma variável de interrupção, como um desconto no ponto de venda para uma alternativa, pode intervir; ou simplesmente 'dormir em uma decisão' pode reduzir a necessidade de excitação e o item é esquecido. Sabe-se que, na compra de serviços, os consumidores podem adiar a tomada de decisão por algum tempo devido ao maior risco percebido inerente à compra, particularmente a incerteza e a perda potencial (Murray, 1991), que são fatores claramente significativos para a situação financeira. Serviços.

Compra: O componente de compra é particularmente relevante não apenas porque é o resultado do processo de tomada de decisão, mas também porque a compra é um aspecto altamente 


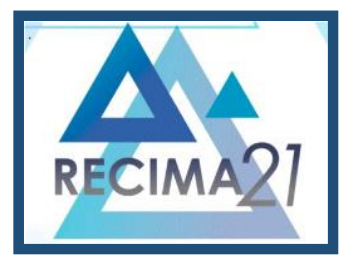

\section{RECIMA21 - REVISTA CIENTÍFICA MULTIDISCIPLINAR}

MODELOS DE TOMADA DE DECISÃO DO CONSUMIDOR, DESTACANDO OS ASPECTOS APLICÁVEIS AOS SERVIÇOS FINANCEIROS E OS QUE REQUEREM ADAPTAÇÃO. Evandro Ferigato

comportamental do processo. A maioria das outras construções é focada internamente como processos de pensamento ou construções baseadas na situação, como experiências passadas.

Avaliação pós-decisão: Essa variável foi alterada da norma de avaliação pós-compra, porque para serviços financeiros é mais difícil para os consumidores fazer avaliações pós-compra. As dificuldades na avaliação dos serviços são bem abordadas na literatura (por exemplo, veja Devlin, 2001; Montfort, Masurel \& Rijn, 2000). É digno de nota o artigo seminal de Darby e Karni (1973), que postulava que bens de credibilidade são aqueles que geralmente não podem ser avaliados mesmo depois de consumidos. Um bom exemplo disso é um investimento financeiro que fornece um retorno de $4 \%$, que, dependendo do contexto econômico e do nível de entendimento do consumidor, pode ser visto como excelente, comum ou calamitoso.

Além disso, se os processos de tomada de decisão são considerados iterativos, podem ser vistos como experiências de teste ou compras, ou podem levar a nenhuma decisão, a análise padrão das construções pós-compra, como dissonância cognitiva, precisa ser expandida para incluir o feedback de a decisão se não houver compra. Esses resultados para o modelo permanecem válidos e muitos são reciclados na mente do consumidor na forma de memória, atitudes e experiências que, por sua vez, podem levar a uma forma de educação e culminar em conhecimentos.

\subsection{RECURSOS ABRANGENTES DO MODELO DE RELEVÂNCIA PARA SERVIÇOS FINANCEIROS}

A discussão anterior sobre os componentes da nova estrutura conceitual destaca alguns dos pontos de partida dos modelos existentes, mas também existem pontos adicionais de diferença que merecem discussão.

Direção: O novo modelo conceitual na Figura 4 representa uma estrutura com uma direcionalidade entrada-processo-saída, semelhante aos modelos anteriores. Os componentes do processo, no entanto, foram alterados a partir da onipresente McCarthy et al. (1997) para permitir múltiplas interações entre qualquer um dos componentes do processo - um retorno às múltiplas relações de Engel et al. (1968) ou o modelo não sequencial de Brinberg e Lutz (1986). Essa abordagem de interação múltipla foi incluída, porque, como discutido anteriormente, há pouca evidência da natureza processual desses conceitos.

Além disso, como observado anteriormente, a natureza da decisão por serviços financeiros costuma ser uma interação complicada entre todos os componentes processuais por um longo período de tempo. Também é reconhecido que as informações de uma pesquisa podem servir como um mecanismo para instigar níveis mais altos de necessidade. Um exemplo hipotético é um indivíduo que considera que é desejável obter um reembolso de impostos no futuro, o que os leva a procurar um contador para assumir encargos administrativos na submissão. Essa busca por informações sobre contadores pode levá-los à descoberta de que o dia final da declaração de impostos é em uma 


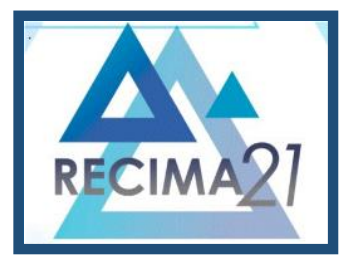

\section{RECIMA21 - REVISTA CIENTÍFICA MULTIDISCIPLINAR}

MODELOS DE TOMADA DE DECISÃO DO CONSUMIDOR, DESTACANDO OS ASPECTOS APLICÁVEIS AOS SERVIÇOS FINANCEIROS E OS QUE REQUEREM ADAPTAÇÃO. Evandro Ferigato

semana. Isso desperta ainda mais a necessidade de consultar um contador e pode alterar a velocidade e a intensidade do processo de tomada de decisão.

Oportunidade e Julgamento: A outra grande divergência em relação aos modelos do passado é que, embora não contenham prazos explícitos, implicam que a maioria das decisões é tomada em prazos comparativamente curtos. Observou-se que os serviços financeiros podem ter decisões que duram muitos anos com várias tentativas fracassadas de compra (Harrison et al., 2006; McKechnie, 1992; McKechnie \& Harrison, 1995). Não é importante se as tentativas fracassadas são consideradas "sem decisão" ou simplesmente uma realização abrangente e oportuna de um ou vários elementos processuais ao longo do tempo. O importante é que os consumidores possam usar o processo de tomada de decisão como uma experiência de aprendizado, ou talvez como uma vitrine de serviços, e 'nenhuma decisão' é uma alternativa viável com muitas iterações possíveis.

Agrupando e articulando: Outra modificação de McCarthy et al. O modelo (1997) é a combinação dos insumos de variáveis psicológicas e sociais para formar as características do consumidor. Embora os constructos subjacentes a essas classificações sejam importantes, para agregar esses componentes à pesquisa, ele fornece clareza conceitual para classificá-los como 'todos os constructos internos ao consumidor' e simplesmente usar os constructos relevantes para o quadro de compra.

Embora a situação da compra possa ser vista como uma característica do consumidor, ela foi separada porque, tecnicamente, é externa ao consumidor. Eventos de vida, ou ocorrências que alteram o 'status de vida' de um consumidor, são incluídos aqui à medida que mudam a situação e podem potencialmente atuar como um instigador para os processos de tomada de decisão. Esse grupo é sugerido pelos pesquisadores de comunicação e comportamentais como um dos motivadores mais poderosos para a mudança comportamental (Mackay, 1994) e, como tal, requer uma construção separada.

A entrada final para a estrutura de tomada de decisão é uma combinação dos dois componentes externos dos 'mixes de marketing' e 'todos os outros estímulos', como mostra o Modelo McCarthy (1997). Esses dois componentes foram combinados no construto 'Fontes de informação', pois, na verdade, é a comunicação dos elementos do mix de marketing ou a forma como os estímulos são recebidos que o tornam uma entrada para os elementos do processo.

Escopo: A natureza da tomada de decisões financeiras, bem como as atuais condições competitivas do mercado, levou a uma suposição adicional dentro do modelo, o qual é chamado de 'escopo'. O escopo neste contexto pode ser descrito como o tipo de soluções alternativas disponíveis. Os modelos iniciais, enquanto usavam estruturas de solução de problemas, foram projetados com um escopo de solução de problemas muito restrito. Por exemplo, Howard e Sheth (1969) projetaram especificamente seu modelo como um processo para ajudar a explicar a escolha da marca, supondo que o consumidor já tivesse tomado à decisão de comprar da categoria de produto. Nesse modelo, a ampliação do escopo para incluir todos os serviços disponíveis diretamente substituíveis na estrutura 


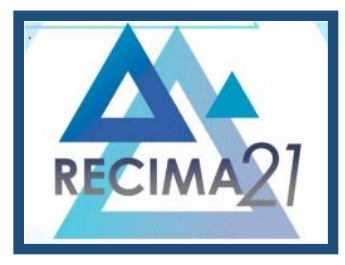

\section{RECIMA21 - REVISTA CIENTÍFICA MULTIDISCIPLINAR}

MODELOS DE TOMADA DE DECISÃO DO CONSUMIDOR, DESTACANDO OS ASPECTOS APLICÁVEIS AOS SERVIÇOS FINANCEIROS E OS QUE REQUEREM ADAPTAÇÃO. Evandro Ferigato

conceitual foi considerada importante porque muitos consumidores são incapazes de distinguir diferenças entre, por exemplo, um planejador financeiro, um gerente de fundos ou mesmo um contador. Esse conceito de escopo é diretamente relevante ao conceito de excitação da necessidade, onde Bruner e Pomazal (1993) reconhecem que o processo pode ser amplo ou estreito em foco. Por exemplo, uma necessidade específica potencialmente poderia ser satisfeita por toda uma classe de mercadorias, enquanto o outro extremo sugere que pode existir uma situação em que apenas uma determinada marca atenda à necessidade.

\section{MÉTODO DE PESQUISA}

\subsection{Problema da Pesquisa}

As necessidades humanas - necessidades do consumidor - são a base de todo o marketing moderno, onde a chave para a sobrevivência de qualquer empresa é a sua habilidade de identificar e satisfazer necessidades do consumidor melhor e antes que a concorrência (Schiffman; Kanuk, 2000). Nesse sentido, Lewis e Bridger (2004, p. 3) alertam que

Não importa o produto que você fabrica ou o serviço que você vende. Se não entender não só o comportamento desses consumidores (...), mas também sua alma, suas estratégias de marketing, que antes eram bem sucedidas, desabarão diante da desconfiança e desinteresse deles, e seus lucros afundarão.

Portanto, estudar e compreender o comportamento dos consumidores é um prérequisito para o sucesso de empresas no mercado (Blackwell; Miniard; Engel, 2005). E, de acordo com estes autores, para compreender o comportamento do consumidor, é necessário saber o que se passa em sua mente, isto porque não só as atividades físicas, como também as atividades mentais realizadas por clientes (Sheth; Mittal; Newman, 2001), juntamento com o desenvolvimento de uma investigação envolvendo os aspectos emocionais do comportamento do consumidor encontra eco, na medida em que algumas das principais publicações científicas internacionais na área do consumidor apresentam um número significativo de estudos com esta temática e exame de todos os artigos nos anais dos Encontros Anuais da Associação Nacional dos Programas de Pós-Graduação em Administração (ENANPAD) foi constatado que dos artigos publicados na divisão de marketing, trataram de algum dos elementos envolvidos neste estudo.

\section{ANÁLISES}

\subsection{População e amostra}

Este estudo ocupou-se da investigação dos aspectos emocionais envolvidos no processo decisório de compra do consumidor. Já é notório que as emoções estão ligadas às trocas simbólicas, que são inerentes ao ambiente e aos processos de consumo; e, embora a importância 


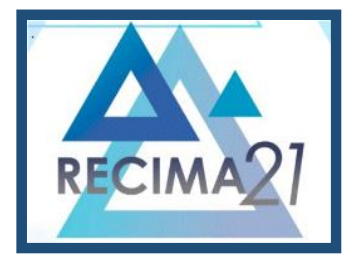

\section{RECIMA21 - REVISTA CIENTÍFICA MULTIDISCIPLINAR}

MODELOS DE TOMADA DE DECISÃO DO CONSUMIDOR, DESTACANDO OS ASPECTOS APLICÁVEIS AOS SERVIÇOS FINANCEIROS E OS QUE REQUEREM ADAPTAÇÃO. Evandro Ferigato

das emoções nas decisões de compra seja reconhecida, ela não é capturada por um grande número de métodos de pesquisa, direcionados para processos racionais (Rossi; Hor-Meyll, 2001), podendo ser mais bem compreendida quando investigada à luz das técnicas qualitativas. Portanto, por julgarse o mais adequado para as características e particularidades deste tema, foi escolhido um método exploratório, com a realização de uma pesquisa de natureza qualitativa.

\section{CONCLUSÃO}

Este artigo analisou Modelos de Tomada de Decisão do Consumidor (MTDC), destacando os aspectos aplicáveis aos serviços financeiros e os que requerem adaptação. A partir de uma revisão da literatura sobre tomada de decisões e serviços financeiros, um novo modelo conceitual foi desenvolvido.

A nova estrutura compreende três componentes principais: entradas, processos e resultados. Os insumos que podem levar à necessidade de excitação incluem a situação da compra (variáveis contextuais e ambientais), características do consumidor (influências psicológicas e sociais) e fontes de informação (marketing e interpessoal).

A seção de processo do modelo inclui a necessidade de excitação, utilidade da informação, desenvolvimento de critérios e avaliação de soluções. Um elemento importante do modelo é o reconhecimento de que esses processos interagem entre si e não com o consumidor após uma progressão linear por esses estágios. O componente final do modelo são os resultados, incluindo a decisão (que pode ser, abortar a compra), a própria compra e a avaliação pós-decisão. Os resultados realimentam os insumos e (indiretamente) os processos, por meio de sua influência nas memórias, atitudes e crenças.

O novo modelo reflete melhor o processo de tomada de decisão iterativo relevante para os consumidores de serviços profissionais, esclarecendo as relações entre os elementos do processo e destacando o papel da informação como uma entrada e um processo-chave na tomada de decisão.

Compreender melhor o processo de tomada de decisão do consumidor permite que os profissionais de marketing desenvolvam estratégias mais eficientes e eficazes para ajudar os consumidores no processo a uma resolução que seja mutuamente benéfica. Os modelos comuns de tomada de decisão do consumidor não são adequados para serviços, e essa nova estrutura conceitual é uma resposta às solicitações de modelos conceituais aprimorados para serviços financeiros em particular.

Mais pesquisas são necessárias para testar os relacionamentos entre as variáveis em diferentes contextos e, assim, permitir o refinamento e / ou validação do modelo.

\section{REFERÊNCIAS}

AAKER, D. A.; KUMAR, V.; DAY, G. S. Pesquisa de marketing. São Paulo: Atlas, 2001. 


\section{RECIMA21 - REVISTA CIENTÍFICA MULTIDISCIPLINAR}

MODELOS DE TOMADA DE DECISÃO DO CONSUMIDOR, DESTACANDO OS ASPECTOS APLICÁVEIS AOS SERVIÇOS FINANCEIROS E OS QUE REQUEREM ADAPTAÇÃO. Evandro Ferigato

ANDREASEN, A. A. Mudanças no status da vida e nas preferências do consumidor e Satisfação. Journal of Consumer Research, v. 11, n. 3, p. 784-794, 1984.

ARIBARG, A.; FOUTZ,N. Z . Triagem baseada em categorias na escolha de produtos complementares. Journal of Marketing Research, Nova Zelândia , v. 46, n. 4, p. 518-530, 2009.

BARDIN, L. Análise de conteúdo. 4. ed. Paris: PUF, 2009.

BATEMAN, H.; KINGSTON, G.; PIGGOTT, J. Poupança forçada: obrigar a aposentadoria privada rendimentos. Cambridge: Cambridge Univ Press, 2001.

BATEMAN, H.; PIGGOTT, J. A abordagem australiana à provisão de renda para aposentadoria. Tóquio: Instituto de Pesquisa Econômica Universidade Hitotsubashi, 2001. v. 38.

BATEMAN, H.; PIGGOTT, J. A política de economia de aposentadoria obrigatória da Austrália: uma visão do novo milênio. New South Wales: Centro de Pesquisa Econômica Aplicada, Universidade de New South Wales, 2000. v. 4.

BELK, R. W. Posses e o Eu Estendido. Journal of Consumer Research, v. 15, n. 2, p. 139, 2003.

BETTMAN, J. R.; JOHNSON, E. J.; PAYNE, J. W. Tomada de decisão do consumidor: manual de comportamento do consumidor, [S.I. : S.n.], 1991. p. 50-84.

BITNER, M. J. Áreas de serviços: o impacto do ambiente físico nos clientes e funcionários. Journal of Marketing, v. 56, p. 57-71, Abril. 1992.

BITNER, M. J.; BOOMS, B. H. Estratégias de Marketing e Estruturas de Organização para Serviços Empresas. In.: DONNELLY. J.; GEORGE, W. R (Eds.). Marketing de serviços. Chicago: Associação Americana de Marketing. 1981. p. 47-51.

BLACK, N. J.; LOCKETT, A.; ENNEW, C. et. al. Consumidor de modelagem Escolha dos canais de distribuição: uma ilustração dos serviços financeiros. International Journal of Bank Marketing, v. 20, n. 4, p. 161-173, 2002.

BLOCH, P. H.; RICHINS, M. L. Compras sem compra: uma investigação do consumidor comportamento de navegação. Avanços na pesquisa do consumidor, v. 10, n. 1, p. 389-393, 1983.

BLOCH, P. H.; SHERRELL, D. L.; RIDGWAY, N. M. Pesquisa de consumidor: uma extensão Estrutura. O Journal of Consumer Research, v. 13, n. 1, p. 119-126, 1986.

BRAY, J. P. Teoria do comportamento do consumidor: abordagens e modelos. Papel de discussão. Bornemouth: Universidade de Bournemouth, 2008. In.: BRINBERG, D.; LUTZ, R. J. Perspectivas sobre metodologia na pesquisa do consumidor. Nova york: Springer-Verlag, 1986.

BRUNER, G. C. Estilos de reconhecimento de problemas e padrões de pesquisa: uma investigação empírica. Journal of Retailing, v. 62, n. 3, p. 281-297, 1986.

BRUNER, G. C. O efeito do estilo de reconhecimento de problemas na busca de informações. Jornal do Academy of Marketing Science, v. 15, n. 4, p. 33-41,1987.

BRUNER, G. C.; POMAZAL, R. J. Reconhecimento de Problemas: a primeira etapa crucial do processo de decisão do consumidor. Journal of Consumer Marketing, v. 5, n. 1, p. 53-63, 1993. 


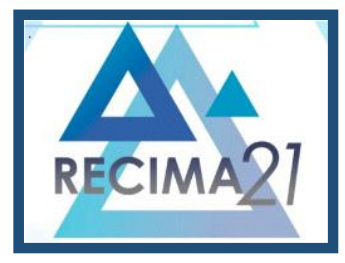

\section{RECIMA21 - REVISTA CIENTÍFICA MULTIDISCIPLINAR}

MODELOS DE TOMADA DE DECISÃO DO CONSUMIDOR, DESTACANDO OS ASPECTOS APLICÁVEIS AOS SERVIÇOS FINANCEIROS E OS QUE REQUEREM ADAPTAÇÃO. Evandro Ferigato

BRYANT, R. C. Pressões demográficas sobre sistemas públicos de pensões e orçamentos governamentais em economias abertas. Washington: Instituição Brookings, 2004.

BYRNE, K. Como os consumidores avaliam o risco em produtos financeiros? Journal of Financial Marketing de serviços, v. 10, n. 1, p. 21-36, 2005.

CANNON, W. B. A sabedoria do corpo. Nova lorque: Norton, 1932

CHUNG-HERRERA, B. G. Necessidades psicológicas dos clientes em diferentes setores de serviços. Journal of Services Marketing, v. 21, n. 4, p. 263-269, 2007.

CHURCHILL JR., G. A.; PETER, J. P. Marketing:criando valor para os clientes. São Paulo: Saraiva, 2005.

COBRA, Marcos. Administração de marketing no Brasil. 3. ed. Rio de Janeiro: Elsevier, 2009.

DARBY, M. R.; KARNI, E. Livre concorrência e a quantidade ideal de fraude. Diário de Direito e Economia, v. 16, n. 1, p. 67-88, 1973.

DEVLIN, J. F. Avaliação do consumidor e vantagem competitiva nos serviços financeiros de varejo A agenda de pesquisa. European Journal of Marketing, v. 35, n. 5/6, p. 639-660, 2001.

DISNEY, R. Podemos nos dar ao luxo de envelhecer?: uma perspectiva sobre a economia do envelhecimento: O MIT Pressione. [S.I. : S.n.], 1996.

DUBOIS, B. Comprendreleconsommateur. Paris: Dalloz, 1994. In.: KARSAKLIAN, Eliane. Comportamento do consumidor. 2. ed. São Paulo: Atlas, 2011.

EARL, P. E.; POTTS, J. Demanda latente e o comprador de navegação. Gerencial e Decisão Economia, v. 21, n. 3-4, p. 111-122, 2000.

EISINGERICH, A. B.; BELL, S. J. Manter o relacionamento com os clientes com alta credibilidade Serviços. Journal of Services Marketing, v. 21, n. 4, p. 253-262, 2007.

ENGEL, J. F.; KOLLAT, D. T.; BLACKWELL, R. D. Comportamento do consumidor. Nova lorque: Holt Rinehart e Winston, 1968.

ENNEW, C. T. Atitudes do consumidor em relação a consultoria financeira independente. Revista Internacional de Marketing Bancário, v. 10, n. 5, p. 4-12, 1993.

FARLEY, J. U.; RING, L. W. Um teste empírico do modelo de comprador de Howard-Sheth Comportamento. Journal of Marketing Research, v. 7, n. 4, p. 427-438, 1970.

GOUGH, O. SOZOU, P. D. Pensões e economias de aposentadoria: análise de cluster de consumidores comportamento e atitudes. O International Journal of Bank Marketing, v. 23, n. 6/7, p. 558, 2005.

GREENLEAF, E. A.; LEHMANN, D. R. Razões para um atraso substancial na decisão do consumidor fazer. Journal of Consumer Research, v. 22 n. 2, p. 186-199, 1995.

HARRISON, T. Editorial: Entendendo o comportamento dos consumidores de serviços financeiros: a agenda de pesquisa. Journal of Financial Services Marketing, v. 8, n. 1, p. 6-10, 2003. 


\section{RECIMA21 - REVISTA CIENTÍFICA MULTIDISCIPLINAR}

MODELOS DE TOMADA DE DECISÃO DO CONSUMIDOR, DESTACANDO OS ASPECTOS APLICÁVEIS AOS SERVIÇOS FINANCEIROS E OS QUE REQUEREM ADAPTAÇÃO. Evandro Ferigato

HARRISON, T.; WAITE, K.; WHITE, P. Análise por paralisia: a decisão de compra da pensão processo. International Journal of Bank Marketing, v. 24, n. 1, p. 5-23, 2006.

HAUSER, J. H.; WERNERFELT, B. Um modelo de custo de avaliação de conjuntos de considerações. Journal of Consumer Research, v. 16, n. 4, p. 393-408, 1990.

HOWARD, J. A.; SHETH, J. N. A teoria do comportamento do comprador. Nova York: Wiley, 1969.

HUNT, S. D.; PAPPAS, J. L. Um teste crucial para o modelo de comportamento do comprador de Howard-Sheth. Journal of Marketing Research (JMR), v. 9, n. 3, p. 346-348, 1972.

JONES, D. G. B.; SHAW, E. H.; MCCLEAN, P. A. As escolas modernas de pensamento de marketing. In.: MACLARAN, P.; SAREN, M.; STERN, B.; TADAJEWSKI, M. (Ed.). O manual SAGE de teoria do marketing. Londres: SAGE Publications Ltd, 2011.

KARSAKLIAN, Eliane. Comportamento do consumidor. 2. ed. São Paulo: Atlas, 2011.

KING, M. F.; HILL, D. J. Os efeitos da disponibilidade alternativa de informações no consumidor estratégias de decisão para serviços profissionais: uma perspectiva transcultural. Journal of Retailing and Consumer Services, v. 4, n. 1, p. 1-11, 1997.

KOTLER, P. Atmosféricos como ferramenta de marketing. Journal of Retailing \& Consumer Services, v. 49, n. 4, p. 48-64, 1973.

KOTLER, P.; ARMSTRONG, G. Princípios do Marketing. 13. ed. São Paulo: Prentice Hall, 2010.

KOTLER, Philip. Administração de marketing: análise, planejamento, implementação e controle. 5 . ed. São Paulo: Atlas, 1998.

KOTLER, Philip; KELLER, Kevin Lane. Administração de marketing. 12. ed. SãoPaulo: Pearson Prentice Hall, 2006.

LAROCHE, M.; KIM, C.; MATSUI, T. Quais heurísticas de decisão são usadas no conjunto de considerações formação? Journal of Consumer Marketing, v. 20, n. 3, p. 192-209, 2003.

LAZARUS, R. S.; FOLKMAN, S. Estresse, apreciação e coroamento. Nova York: Springer Publishing Company, 1984.

LEE, J.; MARLOWE, J. Como os consumidores escolhem uma instituição financeira: tomada de decisão critérios e heurísticas. International Journal of Bank Marketing, v. 21, v. 2, p. 53-71, 1999.

LEE, R.; SKINNER, J. Os baby boomers envelhecidos estourarão o orçamento federal? O Jornal de Perspectivas Econômicas, v. 13, n. 1, p. 117-140, 1999.

LUTZ, R. J. RESEK, R. W. Mais sobre como testar o modelo de comportamento do comprador de Howard-Sheth. Journal of Marketing Research (JMR), v. 9, n. 3, p. 344-345, 1972.

MACKAY, H. Por que as pessoas não ouvem? Chippendale-NSW: Pan Austrália., 1994.

MALHOTRA, N. K. Carga de informações e tomada de decisão do consumidor. Jornal do Consumidor Pesquisa, v. 8, p. 419-430, Mar. 1982. 


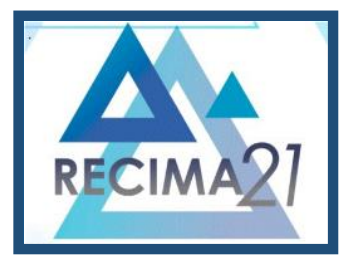

\section{RECIMA21 - REVISTA CIENTÍFICA MULTIDISCIPLINAR}

MODELOS DE TOMADA DE DECISÃO DO CONSUMIDOR, DESTACANDO OS ASPECTOS APLICÁVEIS AOS SERVIÇOS FINANCEIROS E OS QUE REQUEREM ADAPTAÇÃO. Evandro Ferigato

MALHOTRA, Naresh K. Introdução à pesquisa de marketing. São Paulo: Pearson Prentice Hall, 2005.

MARCONI, Maria de Andrade; LAKATOS. Eva Maria. Fundamentos de metodologia científica. 7. ed. São Paulo: Atlas 2010.

MASLOW, A. H. Motivação e personalidade. 2. ed. Nova lorque: Harper \& Row, 1970.

MASLOW, A. H. Uma teoria da motivação humana. Psychological Review, v. 50, n. 4, p. 370-396, 1943.

MATA, R.; NUNES, L. Quando menos é suficiente: envelhecimento cognitivo, pesquisa de informações e qualidade da decisão na escolha do consumidor. Psicologia e envelhecimento, v. 25, n. 2, p. 289, 2010.

MCCARTHY, J. E.; PERREAULT, W. D.; Quester, P. G. Marketing básico: uma gestão abordagem. Sydney: Irwin, 1997.

MCCOLL-KENNEDY, J. R.; Richard, E.; FETTER, J. Dimensões do comportamento de pesquisa do consumidor em Serviços. Journal of Services Marketing, v. 13, n. 3, p. 242-265, 1999. DOI: 10.1108/08876049910273871

MCKECHNIE, S. Comportamento de compra do consumidor em serviços financeiros: uma visão geral. Internacional Journal of Bank Marketing, v. 10, n. 5, p. 5-39, 1992.

MCKECHNIE, S.; HARRISON, T. Compreendendo consumidores e mercados. In.: ENNEW, C. T.; WATKINS, T.; WRIGHT, M. (Eds.). Serviços financeiros de marketing. 2. ed. p. 33-59. Oxford: Butterworth-Heinemann, 1995.

MERGENHAGEN, P. Transições de segmentação: marketing para consumidores durante mudanças na vida. Ithaca NY: American Demographics Books, 1995.

MICHEL, Maria Helena. Metodologia e pesquisa científica em ciências sociais. 2. ed. São Paulo: Atlas, 2009.

MILKMAN, K. L.; CHUGH, D.; BAZERMAN, M. H. Como a tomada de decisão pode ser melhorada? Perspectivas em Ciências Psicológicas, v. 4, n. 4, p. 379-383, 2009.

MITRA, K.; REISS, M. C.; CAPELLA, L. M. Um exame do risco percebido, informações intenções de pesquisa e comportamento nos serviços de pesquisa, experiência e credibilidade. Journal of Services Marketing, v. 13, n. 3, p. 208-228, 1999. DOI: 10.1108/08876049910273763.

MONTFORT, K. V.; MASUREL, E.; RIJN, I. .V. Satisfação de Serviço: Uma Análise Empírica de Satisfação do Consumidor em Serviços Financeiros. O Service Industries Journal, v. 20, n. 3, p. 8094, 2000. DOI: 10.1080/02642060000000033.

MURRAY, K. B. Um teste da teoria do marketing de serviços: aquisição de informações do consumidor Atividades. Journal of Marketing, v. 55, p. 10-25, Jan. 1991.

NEAL, C.; QUESTER, P. G.; HAWKINS, D. Comportamento do consumidor: implicações para estratégia de marketing. 4. ed. North Ryde-NSW: McGraw-Hill, 2006.

NICÓSIA, F. M. Processos de decisão do consumidor: implicações de marketing e publicidade. [S. I.: S. n.], 1966. 


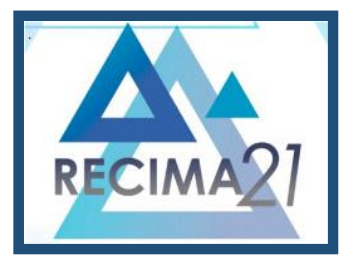

\section{RECIMA21 - REVISTA CIENTÍFICA MULTIDISCIPLINAR}

MODELOS DE TOMADA DE DECISÃO DO CONSUMIDOR, DESTACANDO OS ASPECTOS APLICÁVEIS AOS SERVIÇOS FINANCEIROS E OS QUE REQUEREM ADAPTAÇÃO. Evandro Ferigato

OLIVER, R. L. Um modelo cognitivo dos antecedentes e consequências da satisfação decisões. Journal of Marketing Research, v. 17, p. 460-469, 1980.

OLSHAVSKY, R. W.; GRANBOIS, D. H. Tomada de decisão do consumidor - fato ou ficção? Diário Pesquisa do Consumidor, v. 6, n. 2, p. 93-100, 1979.

PAYNE, J. W.; BETTMAN, J. R.; JOHNSON, E. J. Seleção de estratégia adaptativa na decisão Fazer. Journal of Experimental Psychology: Learning, Memory, and Cognition, v. 14, n. 3, p. 534-552, 1988.

PFEIFFER, J.; RIEDL, R.; ROTHLAUF, F. Sobre a relação entre auxílios interativos à decisão e estratégias de decisão: uma análise teórica. Tagung: Wirtschaftsinformatik, 2009.

PHILLIPS, H.; BRADSHAW, R. Como os clientes realmente compram: interação do cliente com o Ponto de venda. Journal of Market Research Society, v. 35, n. 1, p. 51-62, 1993.

PLOUS, S. A psicologia do julgamento e tomada de decisão. Nova York: McGraw-Hill, 1993.

RICHERS, Raimer. O enigmático mais indispensável consumidor: teoria e prática. Revista da Administração, jul./set. 1984.

RICKWOOD, C.; WHITE, L. Tomada de decisão pré-compra para um serviço complexo: aposentadoria planejamento. Journal of Services Marketing, v. 23, n. 3, p. 145-153, 2009. DOI: $10.1108 / 08876040910955152$.

SAMARA, Beatriz S.; MORSCH, Marco A. Comportamento do consumidor: conceitos e casos. São Paulo: Prentice Hall, 2005.

SCHEWE, C. D.; .MEREDITH, G E. Cavando fundo para encantar o consumidor adulto maduro. Gerenciamento de Marketing, v. 3, n. 3, p. 20-35, 1994.

SCHIFFMAN, Lean G.; KANUK, Leslie L. Comportamento do consumidor. 9. ed. Rio de Janeiro: LTC, 2009.

SHETH, N.; JAGDISH, Mittal Banwari; NEWMAN, I. Bruce. Comportamento do cliente: indo além do comportamento do consumidor. São Paulo: Atlas, 2001.

SIMON, H. A. Modelos de homem. Nova York: Wiley, 1957.

SIMON, H. A. Um modelo comportamental de escolha racional. A revista trimestral de economia, v. 69, n. 1, p. 99-118, 1955.

SOLOMON, Michael R. O comportamento do consumidor: comprando, possuindo e sendo. 9. ed. Porto Alegre: Bookman, 2011.

TAYLOR, J.; GUTMAN, J. Uma reinterpretação do teste de Farley e Ring sobre o Howard-Sheth modelo de comportamento do comprador. Avanços na pesquisa do consumidor, v. 1, n. 1, p. 438446, 1974.

TUCK, M. Como escolhemos? Londres: Methuen \& Co Ltd, 1976.

TYLOR, E. Primitive Culture. In.: DUBOIS, B. Comprendre le Consommateur. Paris: Dalloz, 1994. 


\section{RECIMA21 - REVISTA CIENTÍFICA MULTIDISCIPLINAR}

MODELOS DE TOMADA DE DECISÃO DO CONSUMIDOR, DESTACANDO OS ASPECTOS APLICÁVEIS AOS SERVIÇOS FINANCEIROS E OS QUE REQUEREM ADAPTAÇÃO. Evandro Ferigato

WILTON, P. C.; .MYERS, J G. Efeitos de tarefas, expectativas e avaliação de informações em Utilização da informação. Journal of Consumer Research, v. 12, n. 4, p. 469-486, 1986.

WIRTZ, J.; MATTILA, A. S. Os efeitos da experiência do consumidor no tamanho e no serviço evocados fidelidade. Journal of Services Marketing, v. 17, n. 7, p. 649-665, 2003.

WITTE, E. Pesquisa de campo sobre processos complexos de tomada de decisão - o teorema da fase. Estudos Internacionais de Gestão e Organização, v. 2, n. 2, p. 156-182, 1972.

YIN, R. K. Estudo de caso:planejamento e métodos. 2. ed. Porto Alegre: Bookman, 2001.

YOON, C.; COLE, C. A.; LEE, M. P. Tomada de decisão e envelhecimento do consumidor: atual conhecimento e direções futuras. Journal of Consumer Psychology, v. 19, n. 1, p. 2-16, 2009. 